\title{
IMAGEM CORPORAL E CONSTRUÇÃO DA IDENTIDADE NA INFÂNCIA SOB UMA PERSPECTIVA PEDAGÓGICA
}

\author{
Paula Gomes dos Santos ${ }^{1}$ \\ Kátia Regina Xavier Pereira da Silva²
}

\begin{abstract}
RESUMO: Este artigo tem como foco a imagem corporal e a identidade de crianças, entre 5 e 7 anos de idade na Educação Infantil e no 10 ano do Ensino Fundamental. O objetivo do estudo é identificar e analisar produções científicas brasileiras que tratam os conceitos imagem corporal e identidade sob uma perspectiva pedagógica. Utilizou-se a técnica de revisão sistemática de literatura para a busca em três repositórios on-line: Google Acadêmico, Scielo e Periódicos Capes, no período compreendido entre os anos de 2007 e 2017. Os resultados convergem para propostas pedagógicas relacionadas à inserção de brincadeiras e jogos no cotidiano escolar como meios fundamentais para o desenvolvimento da imagem corporal e da construção da identidade na infância, e atividades relacionadas à representação gráfica. Apontaram, também, a prática psicomotora como instrumento pedagógico para o desenvolvimento da criança, em sua totalidade.
\end{abstract}

Palavras-chave: Imagem corporal. Identidade infantil. Educação infantil.

\section{BODY IMAGE AND CONSTRUCTION OF IDENTITY IN CHILDREN UNDER A PEDAGOGICAL PERSPECTIVE}

ABSTRACT: This article focuses on the body image and the identity of children, between five and seven years of age in Early Childhood Education and in the 1st year of Elementary School. The objective of the study is to identify and analyze Brazilian scientific productions that treat the concepts body image and social identity from a pedagogical perspective. The methodology of systematic literature review was used to search three online repositories: Google Academic, Scielo and Periodical Capes, in the period between 2007 and 2017. The results converge to pedagogical proposals related to the insertion of games and games in school life as a fundamental means for the development of body image and the construction of identity in childhood, and activities related to graphic representation. They also pointed out the psychomotor practice as a pedagogical tool for the development of the child, in its totality.

Keywords: Body image. Identity of children. Early Childhood Education.

\footnotetext{
${ }^{1}$ Graduada em História. Mestranda do Programa de Pós-Graduação em Educação Básica pela Universidade Estadual do Rio de Janeiro (UERJ)- Maracanã. Rio de Janeiro - RJ/ Brasil. e-mail: paulagdsan@gmail.com

2 Doutora em Educação. Docente do Mestrado Profissional em Práticas de Educação Básica, Programa de Pósgraduação em Ciências Médicas da Universidade Estadual do Rio de Janeiro (UERJ) - Maracanã. Rio de JaneiroRJ/ Brasil. e-mail: katiarxsilva@globo.com
} 


\section{IMAGEN CORPORAL Y CONSTRUCCIÓN DE LA IDENTIDAD EN LA INFANCIA EN UNA PERSPECTIVA PEDAGÓGICA}

RESUMEN: El objeto de estudio de este artículo es la imagen corporal y la identidad de niños, entre 5 y 7 años de edad en la Educación Infantil y en el 1 으o año de la Enseñanza Fundamental. El objetivo del estudio es identificar y analizar producciones científicas brasileñas que tratan los conceptos imagen corporal e identidad desde una perspectiva pedagógica. Se utilizó la técnica de revisión sistemática de literatura para la búsqueda en tres repositorios: Google Académico, Scielo y Periódicos Capes, en el período entre los años de 2007 y 2017. Los resultados convergen para propuestas pedagógicas relacionadas a la inserción de juegos en el cotidiano escolar como medios fundamentales para el desarrollo de la imagen corporal y la construcción de la identidad en la infancia, y las actividades relacionadas con la representación gráfica. También apuntaron la práctica psicomotora como instrumento pedagógico para el desarrollo del niño, en su totalidad.

Palabras clave: Imagen corporal. Identidad del niño. Educación Infantil.

\section{Introdução}

Este artigo resulta de um estudo que teve como objetivo geral identificar e analisar, em repositórios on-line (Google Acadêmico, Scielo e Periódicos Capes), produções científicas brasileiras elaboradas nos últimos dez anos (período entre 2007 e 2017) que tratam os conceitos imagem corporal e identidade sob uma perspectiva pedagógica, no contexto da Educação Infantil e da alfabetização. Como objetivos específicos o estudo pretendeu: entender como os conceitos imagem corporal e identidade, no que tange aos âmbitos pedagógicos da Educação Infantil e da alfabetização, têm sido abordados pela comunidade científica; identificar, nos trabalhos científicos, propostas de práticas pedagógicas que auxiliem no desenvolvimento da imagem corporal e na construção da identidade em crianças em espaços formais de ensino e aprendizagem da Educação Infantil e da alfabetização; e organizar e sistematizar os resultados encontrados, buscando uma reflexão baseada em diálogo com a literatura específica.

A psicomotricidade pode ser compreendida como uma ciência de caráter transdisciplinar, o que resulta em perspectivas plurais no que diz respeito a sua conceituação. Isso não quer dizer que os múltiplos discursos não possam convergir. Nesse sentido, conceituase psicomotricidade, neste artigo, em consonância com a definição apresentada pela Sociedade Brasileira de Psicomotricidade. Entende-se, portanto, a psicomotricidade como 
uma ciência que estuda o homem, por meio do seu corpo em movimento, considerando as relações que ele estabelece com o seu mundo interno e com o seu mundo externo (SOCIEDADE BRASILEIRA DE PSICOMOTRICIDADE, [1999?]).

Alguns elementos são considerados essenciais na psicomotricidade, na medida em que se procura compreender o corpo, em sua totalidade: imagem corporal e esquema corporal, estruturação espacial e temporal, lateralidade, equilíbrio, coordenação motora global, coordenação motora fina, ritmo e tônus. Logo, a atuação profissional ancorada na psicomotricidade, seja no âmbito terapêutico ou educacional, tem por pressupostos práticas pautadas no desenvolvimento das estruturas psicomotoras do sujeito.

A imagem corporal encontra-se inserida no conjunto das estruturas psicomotoras. Trata-se de um elemento que deve ser compreendido em um âmbito subjetivo, visto que se relaciona à percepção que o indivíduo tem de seu próprio corpo, ou seja, à representação mental que cada sujeito estabelece sobre seu corpo (SCHILDER, 1980). A imagem corporal sustenta a individualidade do sujeito e constitui o alicerce para o desenvolvimento de sua identidade (TAVARES, 2003). Em outras palavras, a formação da identidade do sujeito é forjada a partir do desenvolvimento da imagem corporal. À vista disso, os conceitos imagem corporal e identidade serão abordados de forma indissociável neste trabalho.

Entende-se que a imagem corporal, por seu sentido subjetivo e complexo, constitua um elemento psicomotor peculiar. Corresponde ao conceito corporal que cada sujeito tem de si e pelo desenvolvimento de sua identidade. Responde, ainda, pela compreensão do desenvolvimento psicomotor individual. Portanto, devido a sua importância, a imagem corporal constitui o objeto de pesquisa eleito. A pesquisa ancorou-se, principalmente, na perspectiva de imagem corporal apresentada por Paul Schilder em seu livro A imagem do corpo: as energias construtivas da psique, publicado pela primeira vez em 1935. Tal livro constitui marco teórico fundamental em estudos sobre a imagem corporal, visto que o conceito fora abordado não só a partir de uma concepção biológica, mas de forma multiperspectivada, ou seja, psicanalítica, filosófica e sociológica.

No âmbito escolar, apesar de se discutir acerca da construção da identidade das crianças, pouco se discorre sobre a imagem corporal infantil. Mesmo existindo a compreensão de que os conceitos são indissociáveis, entende-se que a imagem corporal sustenta a construção da identidade do sujeito. Nesse sentido, compreende-se que em uma educação 
que pretende o desenvolvimento global da criança, o conceito de imagem corporal constitui elemento fundamental da prática pedagógica cotidiana, assim como as atividades que possibilitem o desenvolvimento deste elemento psicomotor.

Contudo, após pesquisa prévia em repositórios on-line, constatou-se que a literatura relacionada ao tema da imagem corporal infantil sob uma perspectiva pedagógica é escassa e a produção relacionada ao tema não se apresenta de forma sistematizada. A proposta da pesquisa emerge de tal contexto.

Pretendeu-se investigar, portanto, os conceitos imagem corporal e identidade, atrelados à prática pedagógica na Educação Infantil e no primeiro ano do Ensino Fundamental, a fim de encontrar respostas para as seguintes indagações: como os conceitos imagem corporal e identidade têm sido abordados sob uma perspectiva pedagógica, no contexto da Educação Infantil e da alfabetização, pela comunidade científica? Que práticas pedagógicas podem auxiliar no processo de desenvolvimento da imagem corporal e da construção da identidade em crianças, entre 5 e 7 anos de idade, que se encontram em espaços formais de ensino e aprendizagem?

Para tal, a presente pesquisa apoiou-se em uma revisão sistemática de literatura, em três repositórios on-line, Google Acadêmico, Scielo e Períodicos Capes, a fim de encontrar respostas para as indagações apresentadas acima, em produções científicas brasileiras elaboradas nos últimos dez anos (período compreendido entre 2007 e 2017).

A partir das respostas encontradas, pretende-se expor, de maneira sistematizada, neste artigo, as propostas de atividades pedagógicas relacionadas ao desenvolvimento da imagem corporal e da construção da identidade em crianças entre 5 e 7 anos de idade. Portanto, o estudo se mostra relevante, visto que pode constituir-se em um instrumento de pesquisa/consulta para professores(as) de Educação Infantil e de classe de alfabetização que queiram inserir tais atividades no exercício da docência.

\section{Método}

A fim de encontrar respostas para as questões norteadoras, o estudo afirmou-se como qualitativo e foi desenvolvido com inspiração na técnica de revisão sistemática (VOSGERAU; ROMANOWSKI, 2014). A revisão avaliou artigos, trabalhos publicados em eventos, dissertações e teses, em língua portuguesa, produzidos entre os anos de 2007 e 2017 em três 
bases de dados: Google Acadêmico, Scielo e Periódicos Capes, repositórios de grande abrangência para as pesquisas em meio eletrônico, no Brasil, visto permitirem o acesso a fontes diversas.

Inicialmente, foram utilizados como parâmetro e limite na estratégia de busca os descritores "imagem corporal" AND "identidade", no título de trabalhos. Além desses, também foram associados outros termos que auxiliaram na delimitação da pesquisa: "Educação Infantil" ou "Ensino Fundamental" e/ou "prática pedagógica". Por meio da leitura dos títulos e/ou resumos, os trabalhos com potencial para responder as interrogações propostas nesta pesquisa de revisão sistemática foram selecionados, sendo a leitura, na íntegra, deixada para momento posterior. Cabe ressaltar que o conceito imagem corporal, na maioria dos trabalhos, se apresentava associado a outros termos, como motricidade, corporeidade, psicomotricidade ou educação psicomotora, e nem sempre aparecia no resumo dos textos.

O processo para seleção dos artigos seguiu alguns critérios de exclusão, a saber:

a) trabalhos repetidos em mais de uma base de dados;

b) cujos resumos não estavam disponíveis ou não apresentassem informações suficientes;

c) que propunham discussões relacionadas ao Ensino Fundamental II, Educação de Jovens e Adultos (EJA), Ensino Superior ou Educação Inclusiva;

d) que não considerassem a abordagem pedagógica;

e) que considerassem populações clínicas de crianças ou adultos;

f) não disponíveis na íntegra;

g) relativos à prática pedagógica em áreas específicas, como dança, artes, teatro e outros;

h) livros, trabalhos de conclusão de curso, resenhas, projetos políticos pedagógicos e outros;

i) publicados antes do período estabelecido para a busca.

A pesquisa nas bases de dados resultou na identificação de 1.743 referências, sendo 962 no Google Acadêmico, 186 no Scielo e 595 no Periódicos Capes. Após aplicação dos critérios de exclusão e leitura de títulos e resumos, 17 foram julgadas pertinentes a partir da 
busca no Google Acadêmico, 1 no Scielo e 2 no Periódicos Capes, totalizando 20 referências. Após leitura completa, 8 foram excluídas, sendo 6 por não apresentarem potencial para responder as interrogações propostas nesta pesquisa e 2 por complicações no acesso ao conteúdo integral. No total, 12 foram consideradas relevantes para a presente pesquisa, sendo 9 artigos, 1 trabalho publicado em Anais de evento e 2 dissertações.

Ressalta-se que os textos selecionados para a discussão atenderam a uma lógica que estabeleceu descritores específicos para análise e a classificação estabelecida emergiu de uma orientação teórico-metodológica singular. Esses aspectos podem ser apontados como limitadores do estudo, já que categorias diferentes seriam evidenciadas em caso de utilização de outros descritores, outro recorte temporal ou diferente teoria utilizada para dar suporte à organização dos dados (SILVA; BRITO, 2015).

\section{Resultados e Discussão}

A partir da análise das 12 referências selecionadas constatou-se que o número de produções ao longo dos últimos dez anos aumentou na segunda metade do período pesquisado (2013-2017), sendo o ano de 2016 aquele que concentrou o maior número de referências (seis). Outro aspecto relevante diz respeito às regiões brasileiras cujas referências selecionadas foram produzidas. Observa-se concentração das produções na região Sudeste, destacando-se os Estados do Rio de Janeiro e de São Paulo.

As propostas pedagógicas com objetivo à promoção do desenvolvimento da imagem corporal e à construção da identidade em crianças entre 5 e 7 anos de idade apresentam muitos pontos de convergência. Em oito referências (CARVALHO et al., 2010; CORNETO, 2015; FALCÃO, 2010; MARCOLAN; LAZZER, 2016; NOGUEIRA, 2016; RIOS, 2016; SAURA, 2014; TALINA; LIMA, 2016) verificam-se propostas relacionadas às brincadeiras e aos jogos. Entretanto, em algumas referências há propostas específicas de brincadeiras ou jogos, como construir e brincar de boneco ou boneca (TALINA; LIMA, 2016), brincar espontaneamente e com materiais não estruturados (SAURA, 2014), brincar de roda (MARCOLAN; LAZZER, 2016) e jogar "comando e imitação" e "esculturas vivas" (NOGUEIRA, 2016), enquanto em outras (CARVALHO et al., 2010; CORNETO, 2015; FALCÃO, 2010; RIOS, 2016), brincar e jogar aparecem de forma abrangente. 
Le Boulch (1987) esclarece que o equilíbrio psicoafetivo da criança passa pelas possibilidades de expressão e comunicação. Entende-se, portanto, que a criança em espaço formal de ensino e aprendizagem desenvolve aspectos psicomotores no ato de brincar. Em outras palavras, além da atividade motora, existem experiências sociais inerentes às brincadeiras infantis. Nesse sentido, Schilder (1980, p. 189) esclarece que "[...] há uma profunda ligação entre a imagem corporal do próprio indivíduo e a dos outros". Ou seja, "[...] a imagem corporal é um fenômeno social”. Logo, quando as crianças brincam entre si, há um intercâmbio no que se refere à imagem corporal, promovendo seu desenvolvimento.

Talina e Lima (2016) e Saura (2014) estabelecem propostas relacionadas a brincadeiras com objetos. Na primeira referência, há um boneco ou uma boneca confeccionado(a) pelas crianças, com materiais diversos, sendo as características físicas (cor da pele, dos cabelos e dos olhos, sexo), psíquicas (sentimentos) e sociais (origem, nome) escolhidas pelas crianças. O(a) boneco(a) passa a integrar a turma de alfabetização e visita as crianças, em suas casas. $\mathrm{Na}$ segunda referência, há propostas relacionadas ao ato de brincar espontaneamente, na primeira infância, em espaço formal de ensino e aprendizagem, mas com a oferta de objetos não estruturados, como tecidos, tábuas, canos, cordas, caixas etc., a fim de que sejam possíveis as explorações e as simbolizações lúdicas (SAURA, 2014).

Calmels (2013) afirma que, assim como se procura entender o homem por meio de estudos sobre o trabalho, para pensar a infância é necessário analisar a criança e sua relação com o jogo e com os brinquedos. Contudo, esclarece que os objetos estruturados para determinados fins, como os brinquedos industrializados e seu uso lúdico, nem sempre atenderão à lógica pré-estabelecida. A relação da criança com o objeto, em circunstância lúdica, se desponta como um recurso de compreensão da realidade do ser, na prática psicomotora (SABOYA, 1995). Nesse sentido, disponibilizar objetos estruturados (ou não) para as crianças inseridas em espaço formal de ensino e aprendizagem e proporcionar momentos regulares para brincar com os mesmos é de extrema relevância, seja na Educação Infantil, ou na classe de alfabetização, na medida em que se proporciona, além de outras aprendizagens, o desenvolvimento da imagem corporal das crianças.

Marcolan e Lazzer (2016) estabelecem uma proposta pedagógica específica: brincar de roda. De acordo com as autoras do artigo, se faz necessário, entre as crianças, o resgate de brincadeiras desconhecidas ou esquecidas, como as brincadeiras de roda. Tais brincadeiras 
precisam ser praticadas em espaços mais amplos e são essencialmente interativas e cooperativas. Ao brincar de roda com o seu grupo, a criança se encontra em processo de socialização, destinando atenção aos seus movimentos e aos movimentos dos outros. Além da motricidade, há a promoção do desenvolvimento da expressão.

De acordo com Le Boulch (1987, p. 46), “os jogos e as atividades de expressão são, portanto, um meio privilegiado de ajudar a criança a equilibrar-se em seu ambiente humano, a comunicar-se e a cooperar". Nesse sentido, tem-se a passagem da expressão livre (manifestação autêntica e espontânea em gestos, atitudes e palavras) à expressão socializada e à comunicação (abertura para a cooperação e a comunicação), na qual a criança se afirma enquanto pessoa e procura a correspondência entre si mesma e o mundo exterior, resultando no encontro com o outro e em equilíbrio para si.

Ao encontrar-se com o outro, ou seja, ao interagir com os seus pares, a criança sistematiza diferentes aprendizagens, inclusive a construção de sua própria identidade (MARCOLAN; LAZZER, 2016). Em outras palavras, ao cooperar com os seus pares, a criança desenvolve conhecimentos quanto às limitações dos outros e as suas próprias limitações. Além disso, destina atenção ao comportamento do outro, à imagem do outro, ao modo de ser do outro. Portanto, ao perceber e entender o outro, a criança desenvolve sua imagem corporal.

A construção da identidade se relaciona, também, com o sentimento de pertencimento. As brincadeiras de roda constituem produção cultural de uma sociedade e brincar de roda remete à memória, ao imaginário de um povo. Em quatro referências (CORNETO, 2015; FALCÃO, 2010; NOGUEIRA, 2016; RIOS, 2016), as propostas pedagógicas se relacionam à inserção de jogos no cotidiano escolar. Contudo, apenas uma (NOGUEIRA, 2016) estabelece proposições de jogos específicos para o desenvolvimento da imagem corporal.

Nogueira (2016) desenvolveu um importante trabalho, no qual expôs resultados de uma pesquisa que objetivou a seleção, em fontes bibliográficas diversas, de diferentes jogos e brincadeiras que privilegiem o desenvolvimento dos elementos psicomotores. Assim, elencou jogos para a construção do esquema corporal e da imagem corporal, para a coordenação motora global, para a coordenação motora fina, para a estruturação espacial e a lateralidade, para a equilibração e tônus muscular, para a percepção de ritmo e temporalidade e para as percepções sensoriais. No que tange à construção do esquema corporal e da imagem corporal, há a proposição de dois jogos: "comando e imitação" e "esculturas vivas". 
O primeiro jogo consiste em o(a) professor(a) dar comandos às crianças para que toquem determinada parte do próprio corpo, sendo que o(a) professor(a) também realiza as ações a fim de que as crianças possam imitá-lo(a). Já o segundo jogo consiste em dispor as crianças em círculo, tendo apenas uma no centro. As demais crianças devem ser vendadas e a que está no centro deve escolher uma pose, se transformando em uma estátua. $\mathrm{O}(\mathrm{a})$ professor(a) descreverá o posicionamento da criança e as demais deverão imitá-la. Ao final, o(a) professor(a) deverá tirar as vendas das crianças, que poderão verificar suas reproduções da estátua original (NOGUEIRA, 2016).

Os jogos, de acordo com quatro referências (CORNETO, 2015; FALCÃO, 2010; NOGUEIRA, 2016; RIOS, 2016), devem fazer parte do cotidiano escolar, seja na Educação Infantil, seja na classe de alfabetização. Nas quatro referências, observa-se um destaque à figura do(a) professor(a) de Educação Infantil e de alfabetização, visto que a inserção de atividades lúdicas no contexto da sala de aula se associa à prática pedagógica desenvolvida por cada docente. Portanto, o(a) professor(a) deve conhecer o potencial de tais práticas, por meio de pesquisas próprias e formações específicas com os seus pares.

Nogueira (2016) esclarece que os jogos constituem experiências ricas, motivadoras e desafiadoras para as crianças, mas ressalta que deve existir uma intencionalidade do(a) educador(a) ao propor as atividades lúdicas. Portanto, inserir práticas pedagógicas lúdicas no planejamento, como os jogos e as brincadeiras, constitui ação fundamental para o(a) professor(a) da Educação Infantil e da classe de alfabetização.

Le Boulch (1987) afirma que o jogo é uma atividade própria da criança e está relacionada ao prazer, ao passo que se constitui essencial para o seu desenvolvimento. Assim, distingue três tipos de jogos: os jogos de imaginação ou simbólicos, os jogos funcionais e os jogos com regras. Os jogos de imaginação ou simbólicos se relacionam à expressão e permitem à criança desenvolver a função imaginativa, implicando em um voltar-se sobre si próprio. Logo, são indispensáveis à formação da criança, em seus aspectos individuais e sociais. Já os jogos funcionais são essenciais para que as crianças desempenhem a necessidade do movimento, proporcionando o desenvolvimento global, visto que a criança é levada a confrontar-se com obstáculos e tarefas reais. Contudo, o aspecto social dos jogos funcionais se manifesta por seu caráter competitivo, se dispondo entre condutas egocêntricas e a cooperação. 
Dessa forma, o(a) professor(a) deve cuidar para que não haja o desenvolvimento da concorrência e do antagonismo coletivos, suscitando em uma imperfeita consciência do corpo e princípios diferentes do sentimento de solidariedade. Contudo, tendo o(a) professor(a) uma boa condução dos jogos, é possível que haja uma progressiva estruturação do grupo, desenvolvendo o respeito a regras estabelecidas (LE BOULCH, 1987).

Os jogos com regras são praticados coletivamente e dependem de um código compartilhado pelos participantes. Eles desempenham um importante papel na socialização, visto que na realização desses jogos, emergem problemas relacionados à liderança ou à rivalidade, o que promove, também, a organização, a comunicação e a cooperação, já que o grupo busca a solução para os conflitos (LE BOULCH, 1987). Assim, o(a) professor(a) desempenha importante papel durante a realização dos jogos com regras, visto que atua na mediação dos conflitos, incentivando a reflexão e a emergência de sentimentos de empatia. No entanto, deve cuidar para que as crianças resolvam melhor suas questões, em um evoluir contínuo. Ou seja, os problemas relacionados à cooperação, entre as crianças menores, não devem ser eliminados ou resolvidos de "forma adulta" (LE BOULCH, 1987, p. 305).

Os(as) professores(as) de Educação Infantil e alfabetização atuam, na maior parte do tempo, como reguladores(as) dos movimentos infantis, chamando atenção das crianças, solicitando que sentem e não se levantem. Contudo, a aprendizagem, a compreensão e a participação não se dão na imobilidade. Pelo contrário, há a necessidade do movimento, da ação, da alteração, dos gestos e do trânsito (MARQUES; MENDES, 2012).

$\mathrm{Na}$ ação performática do corpo, a criança tende a demonstrar suas subjetividades, a consciência que têm sobre si e sobre os outros. "[...] Quanto mais sentir que habita de fato o próprio corpo, maior será a autonomia e consciência dos próprios movimentos" (MARQUES; MENDES, 2012, p. 46). Cabe ao(a) professor(a), portanto, compreender que, no desenvolvimento das atividades cotidianas, no contexto da sala de aula, a criança expõe o seu corpo flexível, repleto de subjetividades. Além disso, o(a) professor(a) precisa compreenderse enquanto sujeito que se encontra em relação de troca com a criança e que nessa relação desenvolve sua imagem corporal.

Quatro referências (CARVALHO et al., 2010; FALCÃO, 2010; NOGUEIRA, 2016; XAVIER et al., 2016) apresentam propostas pedagógicas relacionadas à inserção da psicomotricidade no cotidiano das crianças em espaços formais de ensino e aprendizagem, ou seja, propõem a 
inserção da educação psicomotora no contexto da sala de aula. Rios e Moreira (2016) apresentam proposições relacionadas a atividades que vinculem motricidade e aprendizagem. Logo, ainda que não haja uma clara menção à psicomotricidade, entende-se como o caminho possível.

Das cinco referências que abordam a educação psicomotora (direta ou indiretamente), duas enfatizam a Educação Infantil (FALCÃO, 2010; NOGUEIRA, 2016), enquanto três priorizam o Ensino Fundamental (CARVALHO et al., 2010, RIOS; MOREIRA, 2016; XAVIER et al., 2016), sendo que, em duas (RIOS; MOREIRA, 2016; XAVIER et al., 2016), há a especificação da alfabetização (primeiro ano do Ensino Fundamental). Le Boulch $(1987$, p. 17) esclarece que na educação psicomotora, o objetivo principal é auxiliar a criança a alcançar o que denomina de "imagem do corpo operatório". Explica que o conceito se relaciona não só ao conteúdo, mas à estruturação da relação entre as partes e a totalidade do corpo, como uma unidade organizada, constituída como instrumento da relação com a realidade.

Os autores de cinco referências (CARVALHO et al., 2010; FALCÃO, 2010; NOGUEIRA, 2016; RIOS; MOREIRA, 2016; XAVIER et al., 2016) ressaltam a importância da inserção da educação psicomotora no cotidiano de crianças em espaços formais de ensino e aprendizagem, como instrumento capaz de auxiliar no processo de desenvolvimento infantil, em sua totalidade. Nesse sentido, percebe-se, ao longo dos textos, trechos que corroboram com tal afirmação. Falcão (2010, p. 44) afirma que "[...] a aprendizagem da criança está diretamente ligada ao desenvolvimento psicomotor. Esse é um fator importantíssimo para unir a psicomotricidade à educação".

Rios e Moreira (2016, p. 226) não citam a psicomotricidade, mas salientam a importância dos movimentos corporais autônomos das crianças nas práticas pedagógicas, “[...] sendo assim, a escola deve propor práticas pedagógicas em que ocorram a participação integral da criança, buscando autonomia de movimentos corporais [...]". Ressaltam, ainda, que os movimentos precisam ser compreendidos sob uma perspectiva integracionista: "[...] quando a criança inicia no Ensino Fundamental as interações e a corporeidade precisam ser vistas de forma integrada: cognição, afetividade e movimento" (RIOS; MOREIRA, 2016, p. 225).

Outro fator de destaque em algumas referências (CARVALHO et al., 2010; FALCÃO, 2010; MOREIRA, 2016; NOGUEIRA, 2016; RIOS; XAVIER et al., 2016) é a associação que os autores estabelecem entre educação psicomotora e a promoção do desenvolvimento da 
imagem corporal infantil. Relacionam, portanto a motricidade e a imagem corporal. Tal afirmação pode ser observada no seguinte trecho escrito por Falcão (2010, p. 46): “[...] a psicomotricidade, no cotidiano escolar, visa melhorar e oportunizar à criança o movimento, conscientizando-a do seu próprio corpo, do seu esquema corporal [...]". E no trecho escrito por Nogueira (2016, p. 159): “[...] aspectos observados em psicomotricidade: a percepção do próprio movimento, o reconhecimento do eu, a imagem corporal, a construção do esquema corporal $[\ldots]^{\prime \prime}$.

Falcão (2010) e Nogueira (2016) enfatizam que a psicomotricidade se estabelece como prática por meio de atividades que possibilitem o movimento infantil. Rios e Moreira (2016, p. 232) também elucidam que "[...] a corporeidade é o nosso corpo vivenciado que faz com que nos tornemos significativos para nós mesmos formando uma relação de constante diálogo com os outros corpos expressivos, com os objetos do nosso mundo e conosco mesmo".

Ainda sobre a relação entre psicomotricidade e imagem corporal, observa-se que algumas referências (CARVALHO et al., 2010; RIOS; MOREIRA, 2016; XAVIER et al., 2016) associam a psicomotricidade ao desenvolvimento infantil, em seus múltiplos aspectos. $A$ educação psicomotora, portanto, na perspectiva dos autores, também atua como um instrumento facilitador de múltiplas aprendizagens.

Nesse sentido, Carvalho et al. (2010, p. 204), afirmam que “[...] uma educação [psicomotora] de base da escola primária [...] condiciona todos os aprendizados escolares, levando a criança a tomar consciência do seu próprio corpo, da lateralidade [...]". Xavier et al. $(2016$, p. 86) também esclarecem que “[...] a educação psicomotora deve estar presente na educação infantil, visando incentivar as inteligências múltiplas e favorecer a consciência corporal".

Duas referências (XAVIER et al., 2016; ZORTÉA; KREUTZ; JOHANN, 2008) apresentam propostas pedagógicas relacionadas ao desenvolvimento da imagem corporal e à construção da identidade a partir da representação gráfica, ou seja, dos desenhos produzidos pela criança acerca do seu próprio corpo e do corpo dos outros, como um viés mais objetivo para a análise da imagem corporal infantil. Zortéa, Kreutz e Johann (2008) mencionam o relato oral que a criança faz sobre si mesma. Contudo, opta-se, neste artigo, por analisar somente a proposição relacionada à representação gráfica. 
Xavier et al. (2016) produziram um artigo de revisão narrativa crítica que objetivou refletir sobre a psicomotricidade, a consciência corporal e a representação gráfica de crianças a partir de pesquisa em um repositório on-line. Os autores enfatizam a importância da prática psicomotora para a construção de um aprendizado gráfico, visto que promove o desenvolvimento da consciência corporal e, por conseguinte, a aquisição de habilidades para a representação gráfica, ou seja, para a escrita e para os desenhos. Assim, Xavier et al. (2016) ressaltam que a criança em início de escolarização, ou seja, na alfabetização, externa seu imaginário, principalmente, por desenhos. Portanto, cabe ao professor fornecer tempo adequado para que a criança expresse sua intencionalidade gráfica e não oferecer respostas prontas às situações imaginativas expressas nos desenhos.

As propostas relacionadas aos desenhos autorais fazem parte do cotidiano escolar, seja na Educação Infantil, seja na classe de alfabetização. Crianças, desde a mais tenra idade, gostam de expressar-se por meio do desenho. Costumam desenhar a si mesmas, seus familiares, animais de estimação, entre outros. Ao desenhar a figura humana, a criança projeta conceito sobre si. Logo, o desenho que a criança faz de si e dos outros constitui importante material para o conhecimento da imagem corporal individual.

Zortéa, Kreutz e Johann (2008) buscaram analisar, entre outros aspectos, a imagem corporal de algumas crianças, entre 5 e 7 anos, por meio de desenhos que as mesmas fizeram de si e de amigos a fim de elencarem semelhanças e diferenças entre crianças institucionalizadas e crianças não institucionalizadas. Para tal, utilizaram a Escala de Indicadores Emocionais de Koppitz para a América do Sul. Não há explicações, ao longo do artigo, sobre a escala utilizada, mas o leitor compreende que por meio desse instrumento é possível analisar os desenhos infantis sobre a figura humana. Entende-se que aplicabilidade de escalas e testes psicológicos que envolvem o desenho da figura humana é restrita a psicólogos. Contudo, infere-se que seria importante que os(as) professores(as) conhecessem os materiais específicos de pesquisa para a análise dos desenhos infantis, já que eles fazem parte da prática pedagógica.

No artigo produzido por Zortéa, Kreutz e Johann (2008), o leitor encontra uma tabela de indicadores emocionais que permitem analisar os desenhos de maneira mais objetiva. Contudo, somente ao descreverem alguns resultados, os autores fornecem pistas para a interpretação dos desenhos. Ao estabelecerem uma pesquisa com um grupo de crianças, nos 
moldes propostos por Zortéa, Kreutz e Johann (2008), os pesquisadores não conhecem o grupo pesquisado. Logo, apenas a análise dos desenhos pode auxiliar na descrição da imagem corporal que as crianças têm de si. Contudo, ao transpor a atividade para a sala de aula, entende-se que o(a) professor(a) dispõe de mais instrumentos para confirmar ou refutar as percepções compreendidas por meio dos desenhos.

Entretanto, os desenhos poderiam servir de objetos de análise para que os(as) professores(as) compreendessem melhor as crianças, no que tange à imagem corporal, influenciando em proposições de atividades que estimulassem o desenvolvimento do elemento psicomotor, enfatizando determinados aspectos, de acordo com as dificuldades apresentadas pelas crianças. Nesse sentido, reafirma-se a importância de o(a) professor(a) conhecer os instrumentos específicos de análise dos desenhos infantis.

A última referência analisada (PASCOLATI, 2017) estabelece como proposta pedagógica a análise de livros de imagens, que são materiais literários em que a narrativa se constitui essencialmente pela imagem. Cabe ressaltar que Pascolati (2017) objetiva, em seu artigo, uma reflexão sobre a construção de sentidos no texto infantil a partir das imagens. Ainda que se refira à imagem corporal, há certa dubiedade em seu discurso. Ou seja, o conceito imagem corporal aparece uma vez, em seu artigo, e se refere à imagem visual do corpo. Contudo, Pascolati (2017) propõe reflexões profundas a partir da análise das imagens, como se mostrará a seguir.

Quando o(a) professor(a) se dispõe a ler para/ com as crianças, é importante que haja uma escolha responsável do material literário. Nesse sentido, Pascolati (2017) apresenta e analisa três livros de imagens, oportunizando ao leitor, além de conhecer os livros literários, refletir sobre possíveis abordagens junto às crianças. Os livros intitulados $O$ menino, o jabuti e o menino, de Marcelo Pacheco (2008), Lá vem o homem do saco, de Regina Rennó (2013), e Mamãe trouxe um lobo pra casa!, de Rosa Amanda Strausz (2010), ancoram-se na figura humana, seus sentimentos e suas expressões.

Como o objetivo do presente trabalho não consiste em descrever as referências selecionadas, não cabe a descrição dos livros analisados pela autora. Contudo, propõe-se uma breve reflexão sobre o primeiro livro apresentado por Pascolati (2017) e possíveis abordagens docentes, no que tange à promoção do desenvolvimento da imagem corporal. 
No primeiro livro, intitulado $O$ menino, o jabuti e o menino, tem-se a passagem do tempo, em seu aspecto biológico, marcada nas imagens do menino, que envelhece e morre, ao longo da narrativa, enquanto seu jabuti sobrevive ao tempo e encontra um novo amigo, outro menino. Com a mediação do(a) professor(a), as crianças podem compreender o sentido cíclico da vida do ser humano e desenvolver "[...] toda uma belíssima reflexão sobre a efemeridade do tempo, o escoar da vida, a inevitável chegada da morte e, sobretudo, acerca da felicidade proporcionada pela amizade [...]" (PASCOLATI, 2017, p. 248).

Anteriormente, neste trabalho, ressaltou-se a importância da representação gráfica para as crianças em seus primeiros anos de escolarização, ou seja, a importância dos desenhos que as crianças produzem sobre si e sobre os outros, visto que exprimem suas subjetividades e o conceito que têm sobre si. Doravante, se propõe como prática pedagógica a análise das imagens de figuras humanas, por meio do livro-imagem, como uma complementação à proposição precedente.

Auxiliados pelo(a) professor(a), as crianças podem analisar as expressões dos personagens, conversar sobre os sentimentos que emergem a partir da leitura e compreender as singularidades das reações corporais expressadas por cada sujeito que sente. Compreendese que falar sobre os sentimentos, as emoções, auxilia na organização dos mesmos e, consequentemente, há a promoção do desenvolvimento da imagem corporal.

Calmels (2013) discorre sobre as diferenças entre os heróis infantis do tempo presente e os mais antigos. Reforça que, atualmente, o corpo humano é excluído quando o poder do herói se manifesta. Cita o herói do desenho animado infantil Ben 10, que se transforma em muitos personagens a partir de uma tecnologia alienígena. Compreende-se, portanto, que o ideário infantil do tempo presente se encontra permeado por personagens descorporificados, em desenhos, filmes, livros, gibis e jogos de videogames. Logo, ressalta-se a importância de inserir, na análise de imagens junto às crianças em espaços formais de aprendizagem, seja na Educação Infantil ou na alfabetização, figuras humanas que tenham características (físicas, psíquicas e sociais) realmente humanas.

Após a exposição acerca das propostas pedagógicas voltadas para o desenvolvimento da imagem corporal, pretende-se compreender como os autores das referências selecionadas abordam os conceitos imagem corporal e identidade, em sua relação indissociável. Nesse sentido, Tavares (2003, p. 38) esclarece que "[...] a relevância dos estudos sobre imagem 
corporal está em sua conexão com o desenvolvimento da identidade da pessoa humana [...]". De acordo com Tavares (2003, p. 39), o desenvolvimento da imagem corporal deve ser compreendido como "[...] uma experiência individual e dinâmica subordinada à identidade e à subjetividade de cada sujeito".

Talina e Lima (2016, p. 34) relacionam identidade e imagem corporal a partir da interação social. Afirmam que "[...] o processo de consciência corporal é indispensável para a formação da identidade da criança e se dá em interação social. É com o corpo que a criança elabora suas experiências, organiza sua personalidade e suas relações sociais". Portanto, estabelecem o corpo, em movimento e em interação com o outro, como centro da construção da identidade do sujeito.

Rios e Moreira (2016, p. 231) corroboram com tal perspectiva, ressaltando a importância da inserção de uma educação que privilegie o corpo nos processos escolares. Afirmam que "[...] recolocar o corpo na centralidade que ele tem na construção da nossa identidade e da totalidade de nossa cultura exige criatividade profissional de todos". Logo, cabe aos profissionais dos espaços formais de ensino e aprendizagem considerarem o corpo do sujeito porque o corpo é o sujeito: "[...] o corpo somos nós com nossas individualidades, nossas subjetividades e vontades e acima de tudo nossa interação" (p. 235). Falcão (2010, p. 38) também elucida acerca de uma prática pedagógica que atente para a individualidade do sujeito ao afirmar que "[...] sua interação com o mundo externo é um alimento essencial para a construção de seu mundo interior, ou seja, de sua própria identidade [...], cabendo ao profissional olhar os alunos em sua totalidade, individualidade e em seu trabalho coletivo".

Nas três referências mencionadas acima (FALCÃO, 2010; MOREIRA, 2016; TALINA; LIMA, 2016; RIOS), percebe-se a convergência para dois aspectos comuns, além da clara relação estabelecida entre imagem corporal e identidade. O primeiro aspecto diz respeito à necessidade de atentar para a individualidade, para as subjetividades, de cada criança, no processo de ensino e aprendizagem. Cabe ao professor, portanto, uma prática pedagógica que propicie ao sujeito a percepção de que ele é singular, em suas ações, desejos e interações com os outros. O segundo aspecto está relacionado ao entendimento de que a criança constrói e (re)constrói sua identidade a partir de seu corpo em movimento e em interação social. Nesse sentido, Tavares (2003, p. 80) afirma que “[...] o corpo é um objeto que se constrói como identidade para nós mesmos". Em consonância, Schilder (1980, p. 236) reitera que "[...] ao 
construirmos nosso corpo, nós o espalhamos novamente pelo mundo e o fundimos com outros". Logo, a construção da identidade se dá em meio à interação com o outro, na medida em que, durante a atuação no meio social, há a necessidade de preservação da identidade.

Como a construção da identidade se dá em meio ao processo de socialização, na medida em que o sujeito tem a necessidade de afirmar sua individualidade, as referências apontam os jogos e as brincadeiras como propostas assertivas para a promoção da construção da identidade corporal. Assim, Marcolan e Lazzer (2016) esclarecem que, quando a criança brinca no ambiente escolar, desenvolve-se enquanto sujeito, potencializando sua autonomia e comunicação a partir da socialização, o que contribui para a construção de sua própria identidade.

Carvalho et al. $(2010$, p, 204) ratificam tal afirmação ao elucidarem que "[...] a brincadeira assume importância nesse desenvolvimento, pois é o modo pelo qual as crianças tomam consciência de seus corpos e de suas capacidades". De acordo com os autores, ao brincarem, as crianças lidam com questões importantes relacionadas a aspectos afetivos e sociais, o que proporciona o processo de formação da personalidade e a construção da identidade.

Nogueira (2016, p. 179) apresenta uma proposição semelhante ao afirmar que “[...] todos os jogos permitem a tomada de decisões de forma individual, reforçando sua autoconsciência e capacidade de tomar decisões". A autora esclarece que a imagem corporal é desenvolvida, de acordo com as experiências de movimentos com o corpo, sendo a construção da individualidade parte do processo. Portanto, relaciona imagem corporal, identidade e movimento, a partir dos jogos. Corneto (2015, p. 95) também ressalta acerca da importância dos jogos e das brincadeiras para o desenvolvimento infantil, na medida em que "[...] constituem grande potencial de desenvolvimento individual e social".

Saura (2014, p. 172) relata que as brincadeiras possibilitam a expressão da individualidade do sujeito, visto que oportunizam o conhecimento sobre si e sobre o mundo, por meio de experiências corporais que possibilitem o movimento. Afirma que "[...] o brincar insere-se em uma técnica específica de 'como brincar disso? como jogar isso?', mas permite a manifestação da individualidade dentro do seu movimento".

As três referências que propõem atividades relacionadas à representação gráfica da figura humana (PASCOLATI, 2017; XAVIER et al., 2016; ZORTÉA; KREUTZ; JOHANN, 2008) 
também convergem para a promoção da construção da identidade infantil, além do desenvolvimento da imagem corporal. Quanto a isso, Lapierre e Aucouturier (1984, p. 27) elucidam que, desde a mais tenra idade, a criança busca elaborar desenhos de si, o que, juntamente com a aparição do pronome $e u$, inaugura o processo de acesso à identidade corporal: "[...] É neste momento que aparecem o pronome "eu" e o desenho do corpo (boneco), que marca o acesso da criança a sua identidade corporal". Portanto, têm-se dois apontamentos específicos (que devem ser entendidos em sentido de complementaridade) para a atuação docente que pretende o desenvolvimento da imagem corporal e a construção da identidade do sujeito: a percepção de que cada criança é única e precisa ser valorizada em suas singularidades e subjetividades, e o reconhecimento de uma educação que privilegie o corpo que se movimenta, sente e interage.

Nas palavras de Tavares (2003), percebe-se que identidade corporal e imagem corporal são conceitos que se fundem. Portanto, compreendidos de forma indissociável. Nesse sentido, consideradas as especificidades relacionadas aos conceitos, entende-se que as propostas de atividades estabelecidas pelas referências, voltadas para o desenvolvimento da imagem corporal, necessariamente, estão relacionadas à construção da identidade.

Em síntese, observa-se que a maior parte das referências (CARVALHO et al., 2010; CORNETO, 2015; FALCÃO, 2010; LIMA, 2016; MARCOLAN; LAZZER, 2016; NOGUEIRA, 2016; RIOS, 2016; TALINA; SAURA, 2014) estabelece as brincadeiras e os jogos como práticas pedagógicas específicas para a promoção do desenvolvimento da imagem corporal e da construção da identidade infantil. Apenas Rios e Moreira (2016) estabelecem a relação entre a motricidade e a aprendizagem como prática pedagógica, não especificando atividades, e Pascolati (2017), Xavier et al. (2016) e Zortéa, Kreutz e Johann (2008) apontam o trabalho com imagens relacionadas à figura humana como possível prática pedagógica, sendo que Xavier et al. (2016) e Zortéa, Kreutz e Johann (2008) abordam os desenhos que as crianças fazem sobre a figura humana, enquanto Pascolati (2017) estabelece a análise de imagens de figuras humanas a partir de livros de imagens.

É importante ressaltar que, ainda que algumas referências proponham brincadeiras, jogos, a motricidade ou desenhos autorais infantis como práticas pedagógicas com objetivo ao desenvolvimento da imagem corporal e à construção da identidade em crianças em espaços formais de ensino e aprendizagem, as mesmas referências (CARVALHO et al., 2010; FALCÃO, 
2010; MOREIRA, 2016; NOGUEIRA, 2016; RIOS; XAVIER et al., 2016) relacionam tais atividades à inserção da educação psicomotora no contexto pedagógico das salas de aula. Esse dado conduz a inferência de que a educação psicomotora se mostra relevante para o cotidiano escolar, constituindo um possível caminho para o desenvolvimento da criança, em sua totalidade.

\section{Considerações finais}

Observa-se que, embora haja publicações que associem a imagem corporal a outras temáticas, sobretudo na área da saúde, e que têm como público-alvo os adolescentes, a comunidade científica tem dado pouca atenção a estudos que relacionam imagem corporal e identidade. Os resultados encontrados neste estudo de revisão demonstram lacunas existentes nas publicações referentes ao período pesquisado, quando se trata da discussão sobre imagem corporal nos âmbitos pedagógicos, principalmente na Educação Infantil e na alfabetização.

As proposições estabelecidas pelas referências selecionadas e analisadas evidenciaram a relação entre o conceito imagem corporal e as atividades voltadas para o movimento espontâneo da criança, principalmente por meio dos jogos e das brincadeiras. Apontaram, ainda, a relação entre imagem corporal e identidade, na medida em que elucidaram acerca da possibilidade da afirmação identitária da criança, por meio do movimento, durante as atividades lúdicas.

Nesse sentido, o desenvolvimento e/ou a reestruturação da imagem corporal positiva do sujeito, assim como a construção da identidade, podem ser potencializados por meio de propostas pedagógicas apropriadas. Logo, o(a) professor(a) pode atuar de modo a facilitar o processo de desenvolvimento da imagem corporal e da construção da identidade, na medida em que considerar a singularidade de cada criança, em seus aspectos fisiológico, psíquico, afetivo e social, trazendo à cena pedagógica o corpo, compreendido em sua totalidade, e considerando o movimento como categoria fundamental no processo de ensino e aprendizagem.

Portanto, o presente estudo aponta a relevância da implementação das propostas pedagógicas descritas ao longo do artigo e de outras práticas que objetivem a conexão entre o processo de ensino e aprendizagem e o movimento corporal infantil, principalmente no 
contexto da sala de aula. Sugere, também, a realização de atividades de pesquisa que privilegiem a reflexão acerca dos conceitos imagem corporal e identidade, associados à categoria movimento, no bojo das práticas pedagógicas implementadas.

Assim, recomenda-se o desenvolvimento de pesquisas qualitativas, longitudinais e observacionais para acompanhar a implementação das propostas e verificar em que medida estas impactam no desenvolvimento da imagem corporal dos estudantes, bem como a realização de pesquisas quantitativas a fim de se compreender como os estudantes representam a imagem corporal, a partir de instrumentos validados para este fim. Ressaltase, ainda, a necessidade de formação de professores para a educação psicomotora, capazes de implementar ações voltadas para o desenvolvimento da imagem corporal e para a construção da identidade e refletir sobre o impacto destas no processo de ensino e aprendizagem.

\section{Referências}

CALMELS, D. Fugas: el fin del cuerpo en los comienzos del milenio. Buenos Aires: Biblos, 2013.

CARVALHO, S. et al. Psicomotricidade e o processo de ensino e aprendizagem: em discussão a formação de professores acerca de tais práticas. Coleção Pesquisa em Educação Física. São Paulo, v. 9, n. 6, p. 203-210, 2010. Disponível em:

<http://www.editorafontoura.com.br/periodico/vol-9/Vol9n6-2010/Vol9n6-2010-pag203a210/Vol9n6-2010-pag-203a210.pdf>. Acesso em: 12 jan. 2018.

CORNETO, N. A importância da ludicidade na infância e o desenvolvimento da criança.

Colloquium Humanarum, Presidente Prudente, v. 12, n. 3, p. 86-96, jul.-set., 2015.

Disponível em:

<http://revistas.unoeste.br/revistas/ojs/index.php/ch/article/view/1419/1536>. Acesso em: 12 jan. 2018.

FALCÃO, H. T. Psicomotricidade na pré-escola: aprendendo com o movimento. 2010. 95 f. Dissertação (Mestrado Profissional em Ensino em Ciências da Saúde e do Meio Ambiente) Centro Universitário de Volta Redonda, Volta Redonda, Rio de Janeiro, 2010. Disponível em: $<$ http://web.unifoa.edu.br/portal_ensino/mestrado/mecsma/arquivos/30.pdf $>$. Acesso em: 12 jan. 2018.

LAPIERRE, A.; AUCOUTURIER, B. Fantasmas corporais e prática psicomotora. São Paulo: Manole, 1984.

LE BOULCH, J. Educação psicomotora: psicocinética na idade escolar. Porto Alegre: Artes Médicas, 1987.

MARCOLAN, S. G.; LAZZER, L. P. A. S. O brincar no ensino fundamental: contribuição para o 
desenvolvimento do aluno. Ágora, Espírito Santo, v. 11, n. 22, p. 109 - 118, jun. 2016. Disponível em: <http://periodicos.ufes.br/agora>. Acesso em: 12 jan. 2018.

MARQUES, C.; MENDES, L. A cultura popular gerando ideias na educação infantil: itinerário pedagógico. São Paulo: ÔZé Editora, 2012.

NOGUEIRA, J. E. G. Contribuições de uma prática voltada para a educação psicomotora na educação infantil. In: II SIMPÓSIO DE EDUCAÇÃO: COTIDIANO, HISTÓRIA E POLÍTICAS. 2016, Volta Redonda. Anais... Volta Redonda, Rio de Janeiro, 2016. p. 158-182. Disponível em: <http://www.educacaolibertaria.com.br/site/anais2/13\%20CONTRIBUI\%C3\%87\%C3\%95ES\% 20DE\%20UMA\%20PR\%C3\%81TICA\%20VOLTADA\%20PARA\%20A\%20EDUCA\%C3\%87\%C3\%83 O\%20PSICOMOTORA\%20NA\%20EDUCA\%C3\%87\%C3\%830\%20INFANTIL\%20.pdf >. Acesso em: 12 jan. 2018.

PACHECO, M. O menino, o jabuti e o menino. São Paulo: Panda Books, 2008.

PASCOLATI, S. Ilustração na literatura infantil. Acta Scientiarum, Maringá, v. 39, n. 3, p. $245-$ 253, jul./set. 2017. Disponível em:

<http://periodicos.uem.br/ojs/index.php/ActaSciLangCult/article/view/35642/pdf>. Acesso em: 12 jan. 2018.

RENNÓ, R. Lá vem o homem do saco. São Paulo: FTD, 2013.

RIOS, F. T. A. Ação do professor do primeiro ano do ensino fundamental: o lugar da corporeidade, da motricidade e dos jogos. 2016. 148 f. Dissertação (Mestrado em Educação) - Universidade Federal do Triângulo Mineiro, Uberaba, 2016. Disponível em:

<http://bdtd.uftm.edu.br/bitstream/tede/462/5/Dissert\%20Fabiola\%20T\%20A\%20Rios. pdf>. Acesso em: 12 jan. 2018.

RIOS, F. T. A.; MOREIRA, W. W. O corpo na escola: qual o seu papel? Revista Triângulo, Minas Gerais, v. 9, n. 2, p. 225 - 237, jul./dez., 2016. Disponível em:

<http://seer.uftm.edu.br/revistaeletronica/index.php/revistatriangulo/article/view/1870/1 860>. Acesso em: 12 jan. 2018.

SABOYA, B. Bases psicomotoras: aspectos neuropsicomotores e relacionais no primeiro ano de vida. Rio de janeiro: Trainel, 1995.

SAURA, S. C. O imaginário do lazer e do lúdico anunciado em práticas espontâneas do corpo brincante. Revista Brasileira de Educação Física e Esporte, São Paulo, v. 28, n. 1, p. 163-175, jan./mar., 2014. Disponível em: <http://www.scielo.br/pdf/rbefe/v28n1/1807-5509-rbefe28-01-00163.pdf>. Acesso em: 12 jan. 2018.

SCHILDER, P. A imagem do corpo: as energias construtivas da psique. São Paulo: Martins Fontes, 1980.

SILVA, K. R. X.; BRITO, L. T. Educação Física: uma revisão sistemática. Ensino, Saúde e Ambiente, v. 8, n. 3, p. 15 - 31, dez., 2015. Disponível em:

$<$ http://ensinosaudeambiente.uff.br/index.php/ensinosaudeambiente/article/view/412/22 4>. Acesso em: 12 jan. 2018.

SOCIEDADE BRASILEIRA DE PSICOMOTRICIDADE. O que é psicomotricidade. Disponível em: <https://psicomotricidade.com.br/sobre/o-que-e-psicomotricidade/>. Acesso em: 16 jan. 2018. 
STRAUSZ, R. A. Mamãe trouxe um lobo pra casa! São Paulo: FTD, 2010.

TALINA, M. D. L.; LIMA, P. E. D. S. Desenvolvimento da imagem corporal no primeiro ano do ensino fundamental. Cadernos da Educação Básica, Rio de Janeiro, v. 1, n. 1, p. 34-46, maio, 2016. Disponível em:

<http://www.cp2.g12.br/ojs/index.php/cadernos/article/view/706/615>. Acesso em: 12 jan. 2018.

TAVARES, M. C. G. C. F. Imagem corporal: conceito e desenvolvimento. Barueri: Manole, 2003.

VOSGERAU, D. S. R.; ROMANOWSKI, J. P. Estudos de revisão: implicações conceituais e metodológicas. Revista Diálogo Educacional, Curitiba, v. 14, n. 14, p. 165 -189, jan./abr., 2014. Disponível em:

<http://www2.pucpr.br/reol/pb/index.php/dialogo?dd1=12623\&dd99=view\&dd98=pb>. Acesso em: 16 jan. 2018.

XAVIER, A. M. et al. Psicomotricidade, consciência corporal e representação gráfica de crianças: uma revisão crítica. Revista Didática Sistêmica, Rio Grande do Sul, v. 18, n. 1, p. 7992, 2016. Disponível em: <https://www.seer.furg.br/redsis/article/view/6523/4562>. Acesso em: 12 jan. 2018.

ZORTÉA, L. E.; KREUTZ, C. M.; JOHANN, R. L. V. O. Imagem corporal em crianças institucionalizadas e em crianças não institucionalizadas. Aletheia, Canoas - RS, v. 27, n. 1, p. 111 - 125, jan./jun., 2008.

Disponível em: <http://www.ulbra.br/upload/04c8c3dd9ac59719d2bdb17490b2a86d.pdf>. Acesso em 12 jan. 2018.

Recebido em: 15/02/2018

Aprovado em: 08/08/2018 